\title{
Viewpoint: Entropy, concept design, and animal-unit equivalence in range management science
}

\author{
DAVID L. SCARNECCHIA
}

Author is Associate Professor, Department of Natural Resource Sciences, Washington State University, Pullman, Wash.

\section{Abstract}

The animal unit has been a multiple-use concept in the natural resource sciences. This paper examines the animal unit as an example of a general process of concept design, a process involving multiple options for defining the concept, and multiple objectives and multiple applications for the concept in range management science. Based on this analysis, the animal unit is abstracted as a unit of energy demand independent of interactive considerations of forage or environment. The proposed definition optimizes the utility and universality of the concept by minimizing confounding in the concept's most important applications. The result is a simplified concept that can be used to explicitly express animal equivalences, and can be used in a web of more complex, interactive concepts and models involving human objectives, natural resources, and livestock. The animal unit and animal-unit equivalent are relatively simple examples of synthetic concepts involving communication that are central to the identity of range management science.

Key Words: stocking density, stocking level, stocking rate, stocking variables, animal impact, substitution ratios, terminology

In the fall of 1974 , as I sat in a physics class at the University of Arizona, the professor moved to the chalkboard and wrote

$$
\mathbf{F}=\mathrm{m} \mathbf{a} \text {. }
$$

Force equals mass times acceleration. "In Newtonian mechanics," he said, "if you know that, you can derive the rest." His statement suggests, at least, the inherent power of equivalence in science. Such insight on equivalence should, one might suspect, have relevance in range management science. But recent writings involving animal-unit equivalence (Perrier 1996, Holechek et al 2001) do not adequately recognize the importance of equivalence in the animal-unit concept. The definitions of the concept in these writings undermine the function of the animal unit in its subsequent applications in range management science. In fact, the lack of care in establishing equivalence in the case of the animal unit is part of a wider, more serious problem of ignoring considerations of concept design in range management science.

This paper examines the importance of the concept of the animal unit in range management science. Essentially, the paper makes the process of defining the concept an example of the gen-

Manuscript accepted 4 Mar. 03.

\section{Resumen}

La unidad animal ha sido un concepto de uso múltiple en la ciencias de recursos naturales. Este artículo examina la unidad animal como un ejemplo de un proceso general de diseño de concepto, un proceso que involucra múltiples opciones para definir el concepto y múltiples objetivos y múltiples aplicaciones para el concepto en la ciencia de manejo de pastizales. Basado en este análisis, la unidad animal es abstraída como una unidad de demanda de energía independiente de las consideraciones interactivas del forraje o el ambiente. La definición propuesta optimiza la utilidad y la universalidad del concepto minimizando la confusión en la aplicación más importante del concepto. El resultado es un concepto simplificado que puede ser usado para expresar explícitamente las equivalencias animal y puede ser usado en una red de conceptos mas complejos e interactivos involucrando los objetivos humanos, los recursos naturales y el ganado. La unidad animal y la unidad-animal equivalente son ejemplos relativamente simples de los conceptos sintéticos que involucran comunicación que es central para la identidad de la ciencia de manejo de pastizales.

eral analytical protocol for the design of basic concepts as tools in range management science. Objectives of the paper are to: (1) examine the possible objectives for, and related uses of, the animal unit as a tool, (2) analyze what statement of equivalence gives the animal-unit concept its greatest analytical power as a tool in the hierarchy of concepts and applications contributing to range management science, and (3) implore heuristic application of the animal unit through its precise, minimally confounded use in range management science.

\section{Communication, Relativity, Divisibility, and \\ Equivalence}

In range management science, the animal unit is fundamentally a concept of convenience and visualization in communication, including analysis. Ecologists don't really need an animal unit because they can describe herbivores in terms of, for example, energy. Units of energy are effective in analysis in ecology, but are relatively ineffective in communication in range management science.

Entomologists have little need for an animal unit because they rarely need to quantify their animals fractionally. They can, for most objectives, view insects numerically, as populations; they can just count them. So the animal unit is useful in range manage- 
ment science partly because some relevant herbivores, (e.g., cattle, or elk), are relatively large in size and influence compared to, for example, insects. In range management science, where larger animals are often involved, an animal unit's fractional divisibility is fundamental in its function.

For its applications in range management science, the animal unit is a conceptual artifact-a synthetic tool for communication, including analysis. It is a tool to aid analysis in management science, to link science and management, and aid in communication between them. Conceptually, an animal unit is a unit, and is distinct from an animal-unit equivalent, which is the quantification of an animal in animal units.

And just as a meter is a tool and a unit of length, an animal unit must be a unit of something. To have clear meaning, it should have precise equivalence to that something. The animal unit itself should be clearly definable, and animal-unit equivalents of animals should be relatively easily measured or modeled.

Choice of precise equivalence for the animal unit is an exercise in concept design. The choice is an important judgment of value in communication, including value in analysis. The choice should serve multiple objectives, including general utility in a diversity of applications for the animal unit as a tool within range management science. Advantages and disadvantages are inherent in each choice of equivalence, so that a value-oriented analysis typical of management science, one based on these design objectives and concept uses, is necessary to make a wellreasoned choice.

\section{Menu of Equivalence}

In past publications, the animal unit has been equated to a variety of different entities. It has been equated, either explicitly in definition, or implicitly in application, to a unit of weight (Stoddart and Smith 1943), metabolic size (e.g., Edwards 1981), energy demand (Scarnecchia and Gaskins 1987), and "impact" (Perrier 1996). The following list includes the preceding conceptualizations of equivalence (hereafter termed definitions), and some other possible definitions.

1. Weight (mass)

2. Metabolic size $\left(\mathrm{W}^{0.75}\right)$

3. Energy demand (abstracted to animal only)

4. Dietary requirements (abstracted to animal only, e.g., protein, energy, etc.)
5. Dietary requirements in a real environment (e.g., protein, energy, etc.)

6. Energy or dry matter intake

7. Impact (Perrier 1996) (intake plus physical effects)

\section{Whole animal-environment effects}

The definitions are arranged in order from the simplest and easiest to measure or model (animal weight), to the most complex, and difficult to model (the whole animal and its complex interactions with its environment). Definitions $1-4$ involve conceptual boundaries such that they describe only the animal, independent of its environment. Definitions 3-4 are abstracted in that, while definable, they are not directly measurable. They are exclusively animal-related models. Definition 5 involves all of the variables in definition 4, plus additional interactions associated with a specific environment, including ambient temperatures, forage characteristics, etc. The still more complex intake model (6) is an animal-forage-environment model. Impact (7) involves intake (6), plus additional, non-intake effects (e.g., trampling) associated with the interaction of the animal in its environment, and (8) is an unlimited model of an animal in its environment.

You will find little consensus in published work on which of these measures or models to equate with an animal unit. In addition to the published concepts of the animal unit involving definitions 1, 2, 3 and 7 referred to above, the animal unit has been implied, used, and sometimes, defined as a unit of intake (6) even back to its earliest days (Jardine and Anderson 1919). If you investigate the published research involving large herbivores, you will find that livestock and wildlife nutritionists have, from time to time applied definitions 4 and 5 as well, for ad hoc objectives related to nutritionally oriented analyses. And the possibility exists that someone may even conceptually equate the animal unit to everything as a "theory of knowledge generation" involving the animal-environment universe (definition 8), as was done by Roe (1997) for carrying capacity.

M. M. Kothmann (personal communication) has characterized the situation with the animal unit in thermodynamic terms as having considerable entropy, presumably implying disciplinary disorder rather than intellectual heat. Settling on any one statement of equivalence could reduce some of this entropy (Hinnant 1994). The choice of equivalence would be from the preceding menu of definitions. But the animal unit is a tool, and one objective of this paper is to analyze which statement of equivalence gives the animal unit its greatest analytical value as a tool. The choice of equivalence should be determined by a management science protocol that determines which equivalence best meets the many past, and especially, present and future applications of the tool.

\section{The Animal Unit - Concept of Many Uses}

The animal unit has been a multiple-use concept. Intuitively, the animal unit must be important in range management science because so many people have tried to make so many different uses of it. The animal unit has been used to:

A. Sum demands of mixed herds of animals within species (Scarnecchia and Gaskins 1987),

B. Sum demands of mixed herds of animals among species,

C. Calculate stocking variables, e.g., stocking density (AU/ha), stocking level (AUD/ha), or grazing pressure (AU/ton),

D. Serve in graphs or models of relationships between stocking variables (e.g., stocking density (AU/ha)), and herbage variables (e.g., herbage growth rate ( $\mathrm{kg} / \mathrm{ha}$-day)),

E. Serve in graphs or models of relationships between stocking variables (e.g., stocking level) and variables related to grazing (e.g., animal intake, or animal impact (Perrier 1996), animal production (e.g., weight change), and range and ranch economics,

F. Express forage supply and forage demand in supply/demand analyses for purposes of range and ranch planning,

G. Sum intakes of herds of animals (Forage and Grazing Terminology Committee 1991),

H. Sum impacts (Perrier 1996) of mixed herds,

I. Describe optimized numbers of animals that meet specific model objectives given specified management conditions (i.e., calculate carrying capacities, (Scarnecchia 1990); and

J. Describe either site-specific or general substitution ratios, or exchange ratios between different species of livestock. (Hobbs and Carpenter 1986).

Essentially, these applications are arranged in order of complexity from the simplest (A) involving summing of relatively simple quantities, to the most complex applications (I and J) involving opti- 
mizations to meet objectives. A judicious choice of equivalence for the animal unit is essential to make the animal unit as useful as possible in these diverse applications, and in others that may arise.

\section{Choice of Equivalence}

Among the first 4 definitions, defining the animal unit as a unit of weight (equivalence definition 1) is the trivial choice. While an animal unit defined in this way is easy to measure, it gives the animal unit no more power in analysis or communication than weights themselves. Even in an early reference where this definition appeared (Stoddart and Smith 1943), it was implicitly based essentially on definition 2 (metabolic size $\left(\mathbf{W}^{0.75}\right)$ ). The metabolic size approach has been used widely in diverse disciplines, but a metabolic size model should be considered a simplified case of an animal demand model (i.e., an animal-unit equivalent model based on equivalence definition 3). Equivalence definition 4 involves other dietary requirements in addition to the energy demand of definition (3), and such a model is considerably more complex than an energy demand model limited to the animal. Also, a multi-nutrient model of dietary requirements, without some kind of integrative submodel, does not have a common currency, and instead involves diverse entities such as energy, protein, dry matter, and minerals.

The most common approach in the second group (definitions 5-8) has been to define an animal unit, or at least implicitly use it, as a unit of animal intake (6), e.g., Forage and Grazing Terminology Committee (1991), and the Society for Range Management (1998). Deciphering the choice of equivalence for the animalunit in the most recent glossary revision of the Society for Range Management (1998) is especially challenging. Those 2 definitions from that glossary (Society for Range Management 1998) show significant entropy themselves, in that they contain references to animal weight, metabolic size, and dry matter intake, rather than energy intake. If the superfluous definitional noise is removed, and the definitions are stripped to their currency of equivalence, the animal unit and the animal-unit equivalent therein are implicitly quantified as (dry matter) intake.

In any case, this choice (intake), and all of the choices in the second group have major problems both in basic concept design and in their applications. All of these definitions involve complicated models, because concepts such as animal intake and animal impact (Perrier 1996) are functions of large numbers of variables.

Nevertheless, the idea of a complex animal-unit concept evidently has so much intuitive appeal that the Forage and Grazing Terminology Committee (1991) adopted it, and Perrier (1996) proposed further broadening the animal unit to be a unit of impact, including animal intake plus other effects. Broadening it to definition number 8 , in which everything about the animal and its environment affect its animal-unit equivalent, much as Roe (1997) has done for carrying capacity, is only a matter of degree. (For an evaluation of the dubious wisdom of this idea for carrying capacity, see Scarnecchia (1998).

Failure to abstract the animal unit by defining it apart from its environment means that, for example, a cow has different animal unit equivalents depending on where it is, what it's eating, and what it's doing. At first, this idea seems integrative and advantageous, because as a unit of intake the animal unit can be used to sum intakes of mixed herds; or as a unit of impact, it can be used to sum impacts of mixed herds. To see the serious disadvantages of these definitions of equivalence in range management science, we need to reexamine the applications $(A-J)$ of the animal unit.

\section{A Second Source of Entropy}

Defining the animal unit as a unit of intake means that any variable that affects an animal's intake affects its animal-unit equivalent. Unpalatable or limited forage can reduce or even eliminate intake, and thereby decrease (even to zero) the number of intake-based animal units stocked in a pasture. This curious, conceptual way of solving overstocking is only one of many examples of how defining the animal unit as a unit of intake is incompatible with most of its applications (A-J). In fact, defining the animal unit as a unit of intake, which is ideal for application $\mathrm{G}$ (summing of intakes), makes the animal unit unsuitable for unconfounded use (Scarnecchia 1996) in all of its simpler applications (A-F).

For example, in graphing a relationship between animal intake and stocking level (expressed using animal units), stocking level, by being expressed in a unit of intake, is confounded with intake, making interpretation of the relationship unclear. Likewise, defining the animal unit as a unit of "impact" (Perrier 1996) is ideal for ad hoc summing of impacts, but makes the animal unit unsuitable for unconfounded use in all of its less complex applications (A-G). If entropy implies unavailability for conversion to work (Reader's Digest 1967), defining the animal unit with these equivalences, and thereby increasing confounding, definitely increases entropy.

How the animal unit is defined, i.e., equated, determines its value in communication, including analysis, in the listed applications. The successive equivalence definitions of the animal unit, from 1 through 8 , involve progressively more integrative synthesis-the definitions get more complex - as one moves down the list. With this increasing complexity, the potential confounding in analytical applications also increases moving down the list.

Also, the communication value of the equivalence definitions apparently increases as one moves down the list. But, in moving progressively from 1 to 8 , as analytical value is increasingly limited by increasing confounding, meaningful communication is increasingly illusory. Because confounding undermines ultimate value in analysis throughout a network of applications, definition of the animal unit as more complex equivalences, such as intake, reduces its actual value in communication. The way to make the animal unit an optimally useful tool for its applications (A through $J$ ) is to enhance its value in communication by involving as much integrative synthesis in its definition as possible, without limiting its analytical value by confounding it with variables involved with its applications.

This design problem involves several concurrent objectives, and can be most effectively accomplished by abstraction of the animal unit as a relatively simple demand model of the animal only. Of the 8 possible definitions listed, number 3 is an example of such a model.

Examining both the list of possible animal-unit equivalences (1-8), and animalunit applications $(A-J)$ in this paper, the general conclusions are:

The farther down the list of equivalence definitions (1-8) that the animal unit is defined, the fewer total unconfounded applications it will have.

Definition 1 (weight) is not advantageous because it is no more analytical or communicative than weight itself.

The metabolic size definition of equivalence (2) has some analytical value, but is the most simplified model (i.e., includes only maintenance) of definition 3 . It does not allow accommodation of different 
classes of animals in different physiological states, (e.g., lactation).

Definition 3 (energy demand) will be limited by confounding in application only in analyses involving basic energetic variables in its structure, such as energy for maintenance, growth, lactation, gestation, or change in body condition. Applications of animal units in analyses involving the partitioned energetics of these physiological activities are currently uncommon in range management science. Even if such analyses do become more common, potential confounding is, in nearly all cases, avoided by the abstracted (demand) character of the animal unit, because, for example, a stocking variable calculated with an abstracted, demand-based animal unit will not be confounded with real, measurable variables such as actual lactation or growth; it will be confounded only with abstracted variables such as energy demand for lactation that contribute to animal-unit equivalents. An animal unit defined as a unit of energy demand will not be a unit of intake or impact, but it can nonetheless be used as a rigorously limited, clearly defined, conceptually unconfounded component of analyses and models of these more complex, interactive concepts.

If it is defined as a unit of energy demand, the animal unit can be applied without confounding in its most important applications, including applications A-J. With this definition, the animal unit is abstracted as a model of energy demand so that the animal-unit equivalent of a given animal is the same independent of its environment. For an example of an energy demand model for beef cattle involving maintenance, growth, gestation, lactation and body condition, useable at 2 different degrees of complexity, see Scarnecchia and Gaskins (1987).

The animal unit should not be confused with more complex species substitution or exchange relationships as has sometimes been done in the past (e.g., Hobbs and Carpenter 1986). The inadvisability of ignoring this distinction has been discussed previously (Scarnecchia 1986).

Making the animal unit a unit of intake, impact, or any animal-forage or animalenvironment model makes its clear, unconfounded application impossible for simpler, but highly important applications including calculating stocking variables, and describing unconfounded relationships between stocking variables and intake, impact, or variables describing animal production. By its abstraction as a unit of energy demand, the animal unit, as a tool, is optimally designed to analyze and communicate concepts we are really interested in-concepts like stocking variables, animal intake, animal impact, animal production variables, carrying capacities and species substitution ratios.

\section{Derive the Rest?}

The animal unit is actually an important concept in the diverse communication, including analysis, of range management science. Even more importantly, the process of its design is an excellent example of the general process of concept design for range management science, a process that serves as a reminder of the synthetic character of the science (Scarnecchia 2003). With an abstracted concept of an animal unit that is equivalent to energy demand, we can apply the animal unit in the analysis of practically all of the interactive animal-plant-environment models in range management science. We cannot exactly derive all of range management science from this statement of equivalence, but we can use the animal unit's quality of divisibility for precise analyses throughout a web of its important analytical applications, and have the advantage of improved communication over less informative variables like animal numbers, animal weights or metabolic size. Application of the animal unit begins with the abstraction of the animal unit as a unit of energy demand, rather than its definition as a real, measurable, interactive concept, such as intake.

Range management science needs formal models of animal-unit equivalents, such as the one developed for beef cattle some years ago (Scarnecchia and Gaskins 1987), for the relevant species of wild and domestic grazers. Tables of animal-unit equivalents can be prepared for easy visualization, but mathematical models are the most compact, and usually the most efficient form to communicate this information for most applications. Organizations such as the Society for Range Management, and committees such as the Forage and Grazing Terminology Committee should pursue development of standardized animal-unit equivalents from documented models for relevant herbivores. That future development depends on an abstracted concept of the animal unit, one advantageously designed as a unit of energy demand.

But these future applications will continue to be enveloped in entropy if the animal unit is actually equated to a real, interactive variable like animal intake, or a complex, interactive concept like animal impact. We should not add to the entropy by re-energizing sub-optimal range management science such as applying the ani- mal unit as a confounded unit of intake or impact, or equating animal-unit equivalents to location-specific species substitution ratios. Authors who pursue ad hoc applications of animal units that engender confounding and add to entropy would do better to consider the implications of the equation $\mathbf{F}=\mathrm{m}$ a of Newtonian mechanics, or equally, consider a sun-filled holiday to bask in the inevitably increasing entropy, and, in either case, derive the rest.

\section{Literature Cited}

Edwards, P.J. 1981. Terms describing aspects of vegetation and its management. Chapter 14 in N. M. Tainton, (ed.). Veld and pasture management in South Africa. Shuter and Stooter (Pty) Ltd., Pietermaritzburg, South Africa.

Forage and Grazing Terminology Committee. 1991. Terminology for grazing lands and grazing animals. Pocahontas Press, Blacksburg, Virg.

Hinnant, R.T. 1994. What is an animal unit? A time to conform. Rangelands. 16:33-35.

Hobbs, N.T. and L.H. Carpenter. 1986. Viewpoint: animal-unit equivalents should be weighted by dietary differences. J. Range Manage. 39:470.

Holechek, J.L., R.D. Pieper, and C.H. Herbel. 2001. Range management, $4^{\text {th }}$ ed. Prentiss Hall, Upper Saddle River, N.J. 587 p.

Jardine, J.T. and M. Anderson. 1919. Range management on the national forests. USDA Bull. 790.

Perrier, G.K. 1996. The animal unit as an ecological concept. Rangelands. 18:30-31.

Reader's Digest. 1967. The Reader's Digest great encyclopedic dictionary.Reader's Digest Assoc., Pleasantville, N.Y. 2092 p.

Roe, E. 1997. Viewpoint: On rangeland carrying capacity. J. Range Manage. 50:467-472.

Scarnecchia, D.L. 1986. Viewpoint: Animal-unit equivalents cannot be meaningfully weighted by indices of dietary overlap. J. Range Manage. 39:471.

Scarnecchia, D.L. 1990. Concepts of carrying capacity and substitution ratios: a systems viewpoint. J. Range Manage. 43:553-555.

Scarnecchia, D.L. 1996. Viewpoint: Concept design in range management science. J. Range Manage. 49:421-424.

Scarnecchia, D.L. 1998. Viewpoint: On objectives, boundaries and rangeland carrying capacity. J. Range Manage. 51:477-478.

Scarnecchia, D.L. 2003. Viewpoint: Empowering diversity: Envisioning designing and developing range management science. J. Range Manage. 56:558-569.

Scarnecchia, D.L. and C.T Gaskins. 1987. Modeling animal-unit equivalents for beef cattle. Agr. Syst. 23:19-26.

Society for Range-Management. 1998. Glossary of terms used in range management. 4th edition. Society for Range Management, Denver, Colo.. 32 p.

Stoddart, L.A., and A.D. Smith. 1943. Range management. McGraw-Hill Book Co., New York, N.Y. 547 p. 